«Системні технології» 4 (129) 2020 «System technologies»

DOI 10.34185/1562-9945-4-129-2020-11

УДК 004.681.2.08

А.Ю. Зимогляд, А.И. Гуда, В.Ю. Царик

\title{
МЕТОД АМПЛИТУДНОЙ МОДУЛЯЦИИ ВЫСОКОЧАСТОТНОГО КОРОННОГО РАЗРЯДА
}

Анотація. Коронний розряд знайшов своє застосування в різних галузях науки і техніки. Коронний розряд, що протікає при високих частотах, застосовується для поверхневого легування металів і напівпровідників, для очищення газів від пилу в складі електростатичних фільтрів, для діагностики станів конструкцій. У статті наводяться результати дослідження з управління розрядом за допомогою амплітудної модуляції.

Ключові слова: коронний розряд, високочастотний коронний розряд, амплітудна модулячія, buck перетворювач.

Вступление. Коронный разряд нашел свое применение в различных отраслях науки и техники. Коронный разряд, протекающий при высоких частотах, применяется для поверхностного легирования металлов и полупроводников, для очистки газов от пыли в составе электростатических фильтров, для диагностики состояний конструкций.

Коронный разряд - это самостоятельный газовый разряд, возникающий в резко неоднородных полях у электродов с большой кривизной поверхности. При коронном разряде ионизационные процессы происходят только вблизи коронирующего электрода. Когда напряженность поля достигает предельного значения, для воздуха это 30 кB/cм, вокруг электрода появляется свечение в виде короны. Зажигание короны может наблюдаться не только по свечению, у коронирующего электрода, а и по скачкообразному возрастанию тока через электроды, до значений порядка $10^{-6}$ ампер [3].

В исследовании рассматривается возможность управления разрядом в диапазоне звуковых частот с помощью амплитудной модуляции.

Цель. Для изучения явлений, возникающих при коронном разряде, а так же для обеспечения высокочастотного коронного разряда и измерения его физических свойств, которые необходимы для постройки моделей и системы управления, был собран аппаратный комплекс. Дан-

(C) Зимогляд А.Ю., Гуда А.И., Царик В.Ю., 2020 
«Системні технології» 4 (129) 2020 «System technologies»

ный аппаратный комплекс включал в себя: генератор высокочастотного коронного разряда, блок питания и модулятор, построенный на преобразователе топологии Buck.

Основная часть. Для создания высокочастотного разряда была применена схема пуш-пул на полевых транзисторах sihg20n50 с внешним кварцевым генератором на 4 МГц (рис. 1).

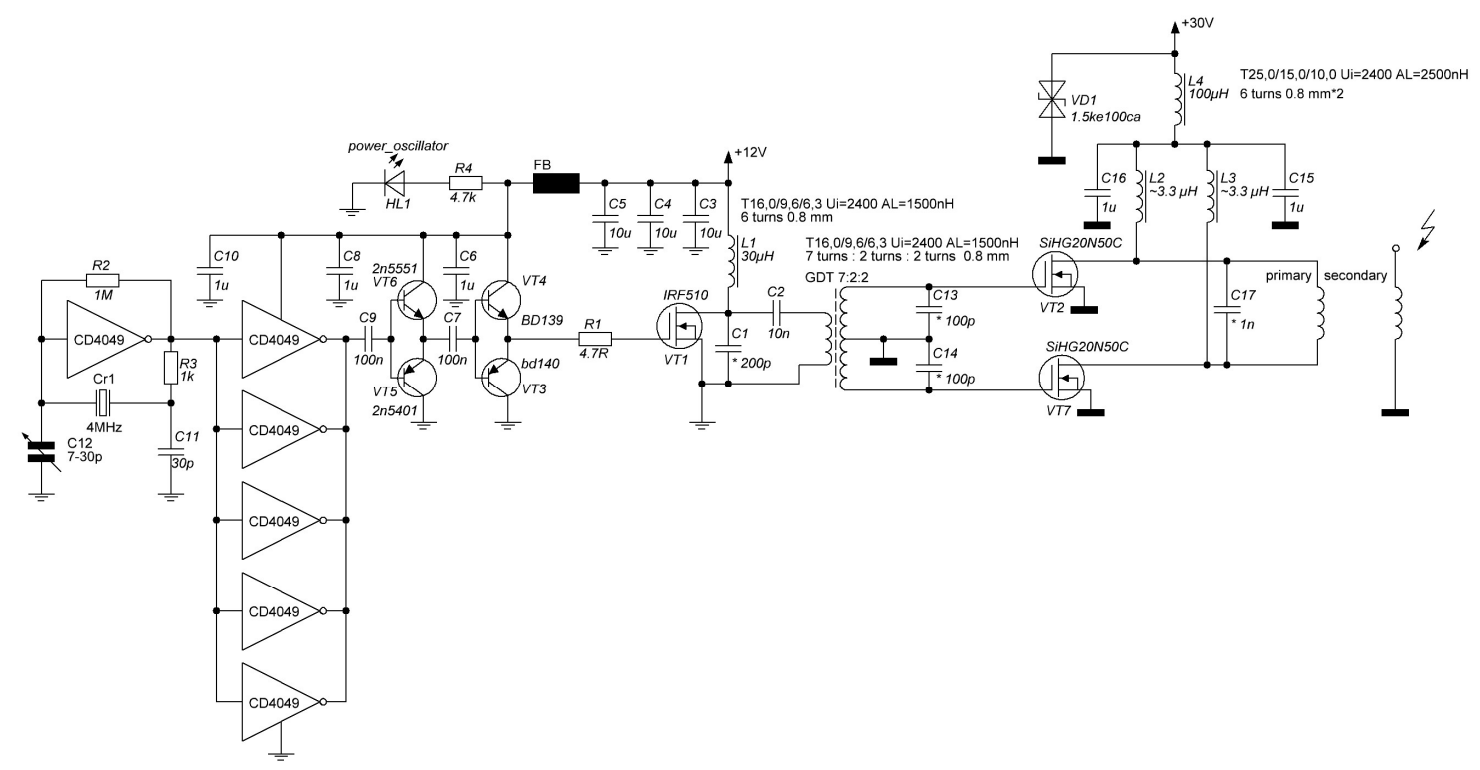

Рисунок 1 - Схема источника высоковольтного, высокочастотного коронного разряда

В представленной схеме кварц подключён по схеме Джорджа Пирса, построенной на одном из шести инверторов микросхемы CD4049. После него находится буфер из пяти оставшихся инверторов. Конденсатором С12 можно изменять в небольших пределах выходную частоту генератора прямоугольного сигнала.

Полученный прямоугольный сигнал усиливается двумя каскадами комплементарных эмиттерных повторителей, которые усиливают сигнал по току и выступают в роли драйвера затвора полевого транзистора VT1.

Транзистор VT1 включен в схему усилителя класса Е. К стоку транзистора подключен дроссель L1, который накапливает энергию. Meжду стоком и истоком транзистора включен конденсатор C1, который обеспечивает мягкое переключение. Конденсатор С2 необходим для блокирования постоянной составляющей, которая присутствует на средней точке между дросселем и стоком. Через этот же конденсатор проходит 
«Системні технології» 4 (129) 2020 «System technologies»

только ВЧ составляющая, которая подается на трансформатор управления затворов транзисторов силовой части.

Трансформатор управления затворов или GDT (Gate Drive Transformer) используется в преобразователях напряжения и предназначен для гальванической изоляции управляющей схемы и силовой части.

После трансформатора управления затвора, точнее на его вторичных обмотках установлены конденсаторы C13 и C14, которые вместе с емкостью затвора и индуктивностью вторичной обмотки создают колебательный контур, предотвращающий линейный режим работы транзисторов.

Осциллограмма сигнала на затворе силового транзистора представлена на рис. 2.

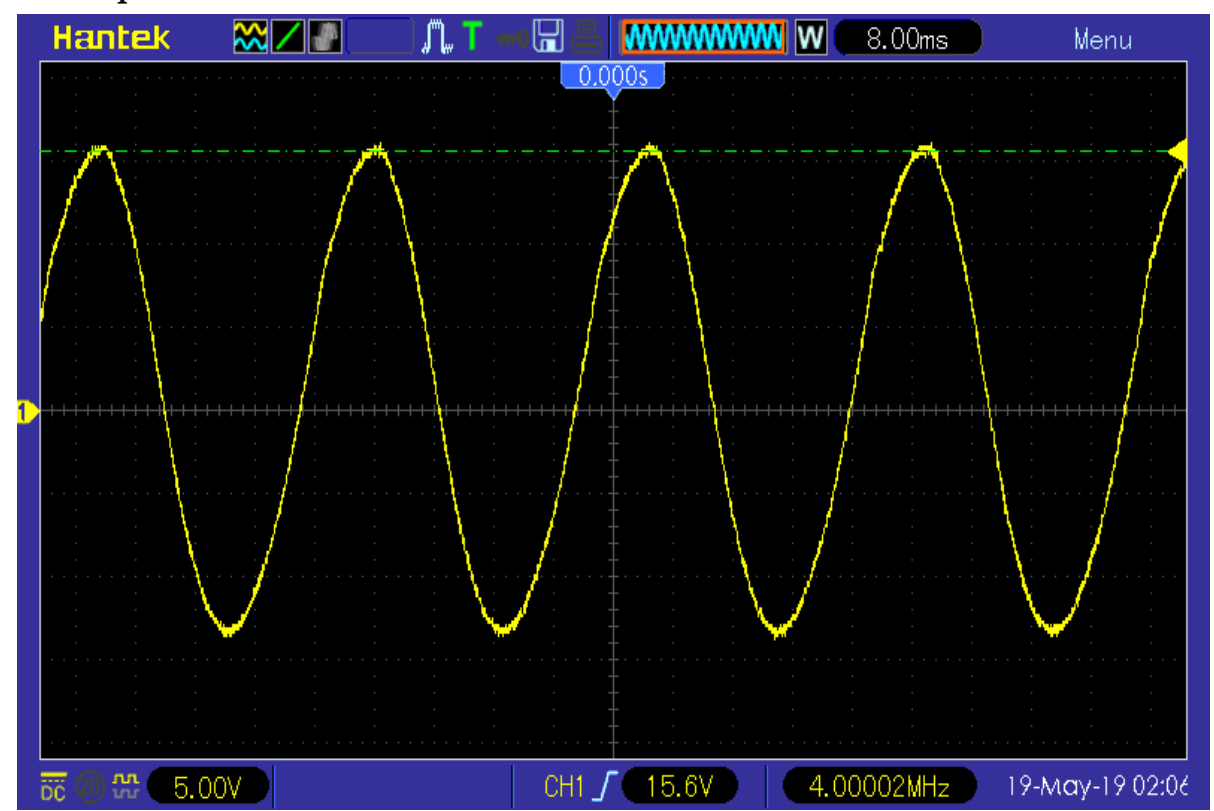

Рисунок 2 - Осциллограмма сигнала на затворе силового транзистора

Как видно из осциллограммы, сигнал имеет амплитуду, достаточную для работы полевого транзистора в ключевом режиме. Время работы в линейном режиме минимально, что существенно повышает КПД схемы в целом.

Дроссели L2, L3 являются нагрузкой для транзисторов VT2 и VT7. Со средней точки дросселей и стоков транзисторов управляется первичная обмотка трансформатора Тесла.

Конденсатор C17 подключенный параллельно первичной обмотки, немного подстраивает частоту первичного контура и согласует с вторичным контуром трансформатора Тесла. 
«Системні технології» 4 (129) 2020 «System technologies»

На выводе вторичной обмотки трансформатора Тесла находится терминал, на котором происходит коронный ВЧ разряд.

Для блокировки ВЧ шума силовой установлен LC фильтр на дросселе L4 и конденсаторах C15, C16. После фильтра так же установлен супрессор для предотвращения высоковольтных выбросов в шину питания.

Общий внешний вид силовой, схемы управления и двух блоков питания представлен на рис. 3.

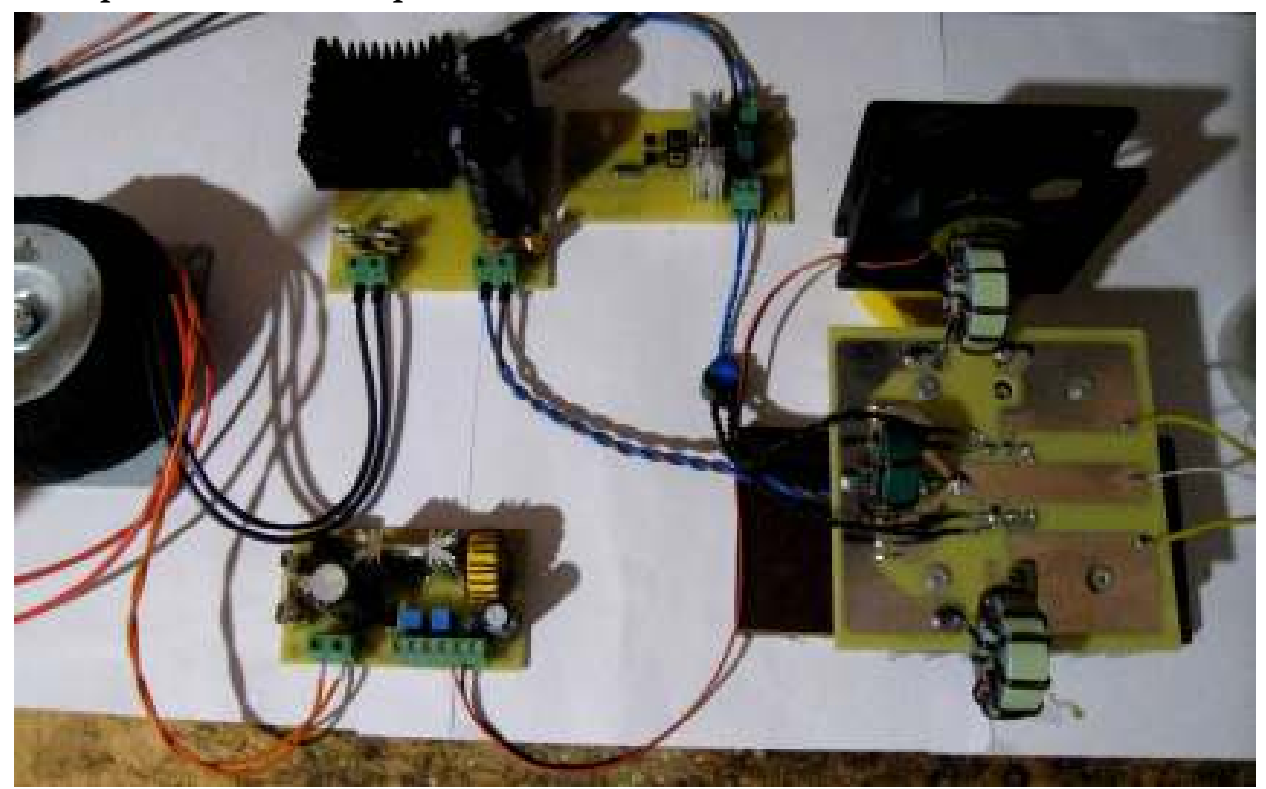

Рисунок 3 - Общий вид установки для получения ВЧ коронного разряда

На рисунке 4 представлен высокочастотный коронный разряд с трансформатора Тесла. Для окрашивания разряда на терминале находится стекло, в качестве источника ионов. Наличие в разряде ионов щелочных металлов обеспечивает окрашивание разряда, что необходимо для фиксации формы разряда. 
«Системні технологіï» 4 (129) 2020 «System technologies»

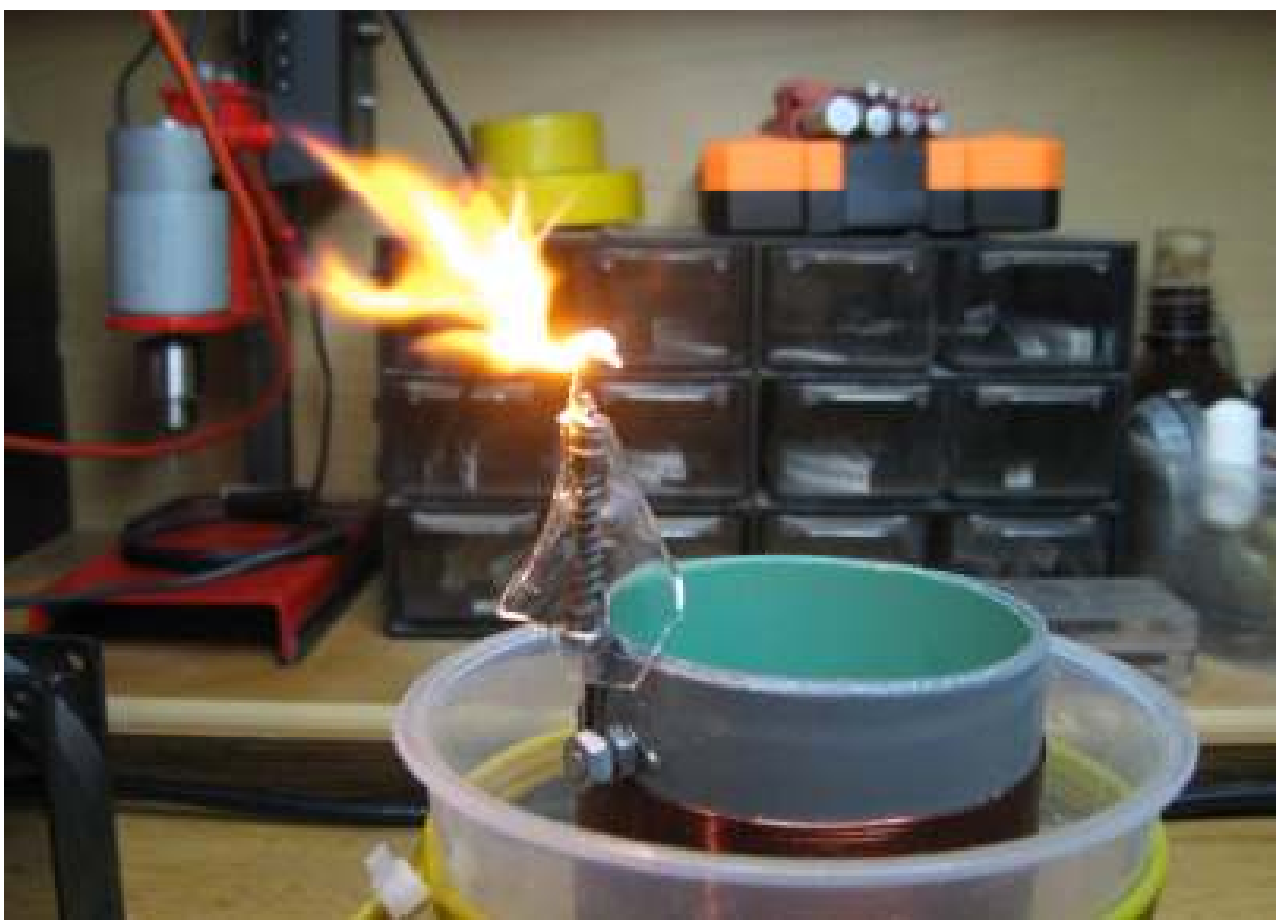

Рисунок 4 - Коронный ВЧ разряд на частоте 4 МГц

После успешного запуска установки и получения устойчивого горения коронного разряда стала актуальной задача модуляции и управления разрядом. Для решения этой задачи был применен метод амплитудной модуляции.

Амплитудная модуляция - вид модуляции, при которой изменяемым параметром несущего сигнала является его амплитуда. Первые опыты передачи речи и музыки с помощью радиоволн методом амплитудной модуляции произвёл в 1906 году американский инженер Р. Фессенден. В его опытах несущая частота 50 кГц радиопередатчика вырабатывалась электромашинным генератором (альтернатором). Для модуляции между генератором и антенной включался угольный микрофон, изменяющий затухание сигнала в цепи.

С 1920 года вместо электромашинных генераторов для генерации несущей частоты стали использоваться генераторы на электронных лампах. Во второй половине 1930-х годов, по мере освоения ультракоротких волн, амплитудная модуляция постепенно начала вытесняться из радиовещания и радиосвязи на УКВ частотной модуляцией [4].

При необходимости модулировать в диапазоне звуковых частот факельный или высокочастотный коронный разряд можно использовать 
модуляцию по шине питания. Для амплитудной модуляции был выбран импульсный преобразователя топологии Buck (рис. 5).

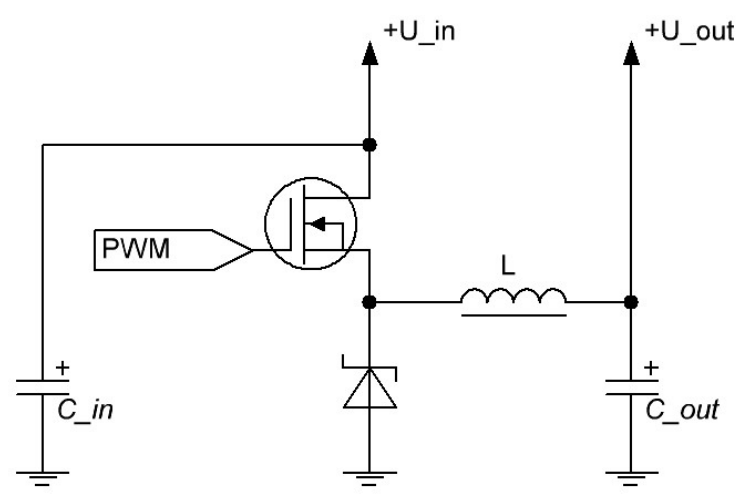

Рисунок 5 - Топологическая схема импульсного Buck преобразователя

Расчет компонентов схемы, а так же режимы работы, влияние нагрузки, можно найти в источниках [5,6,7]. Структурно же модулятор на основе Buck конвертера включен между блоком питания и схемой накачки трансформатора Тесла (рис. 6).

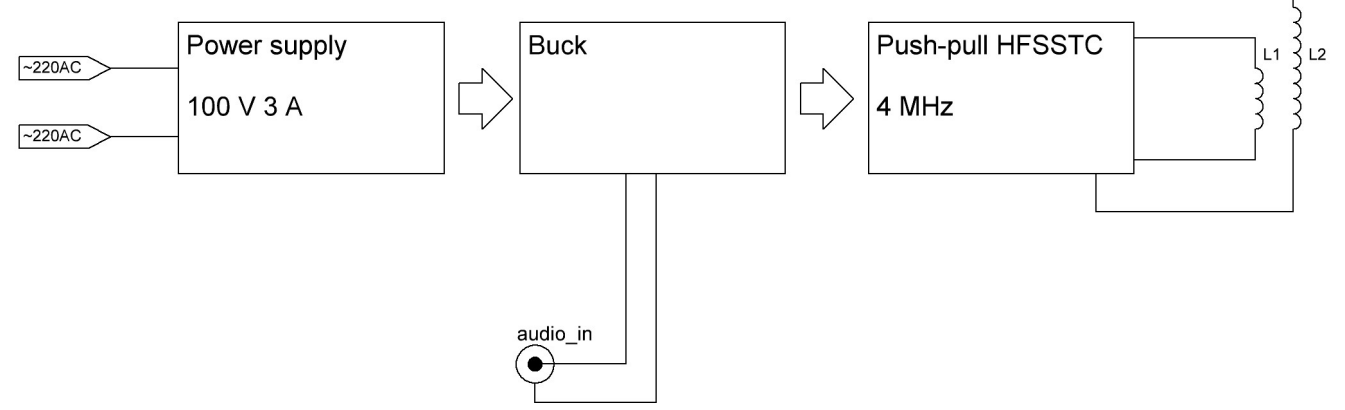

Рисунок 6 - Схема подключения Buck преобразователя, для амплитудной модуляции

Входной сигнал звуковой частоты, подаваемый на Buck конвертер, приводит к изменению амплитуды на шине питания.

Buck преобразователь управляется микросхемой TL494, которая включена в режиме однотактного генератора. Схема представлена на рис. 7. 
«Системні технології» 4 (129) 2020 «System technologies»

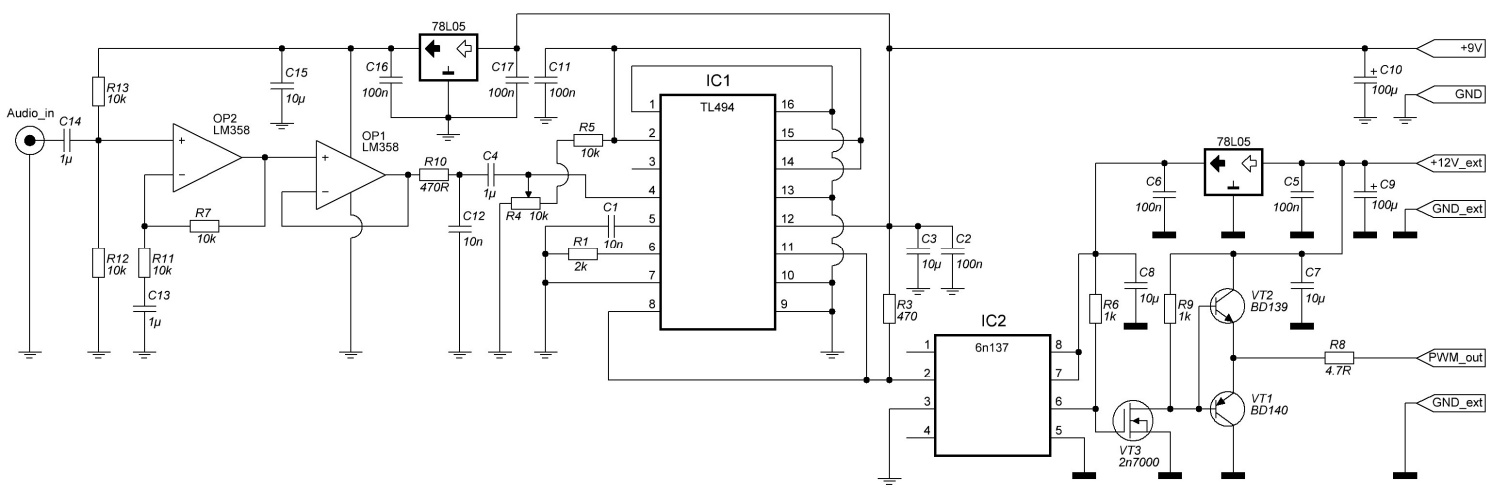

Рисунок 7 - Схема управления силовой Buck преобразователя, для амплитудной модуляции

Входной сигнал звуковой частоты подается на неинвертирующий усилитель выполненный на микросхеме LM358, на котором усиливается в 2 раза и подается на вывод 4 TL494, который отвечает за скважность. Прямоугольный сигнал частотой 50 кГц, с изменяемой в зависимости от входного сигнала скважностью подается на оптодрайвер собранный на оптроне 6N137 и трех дискретных транзисторах. Транзистор 2N7000 выполняет роль инвертора, а также усиливает сигнал с 5 вольт на 12 и уже усиленный сигнал подается на комплементарную пару BD139 / BD140, где усиливается по току.

К выходу оптодрайвера подключается классический асинхронный Buck конвертер после которого изменения в скважности приводят к изменению выходного напряжения (рис. 8,9).

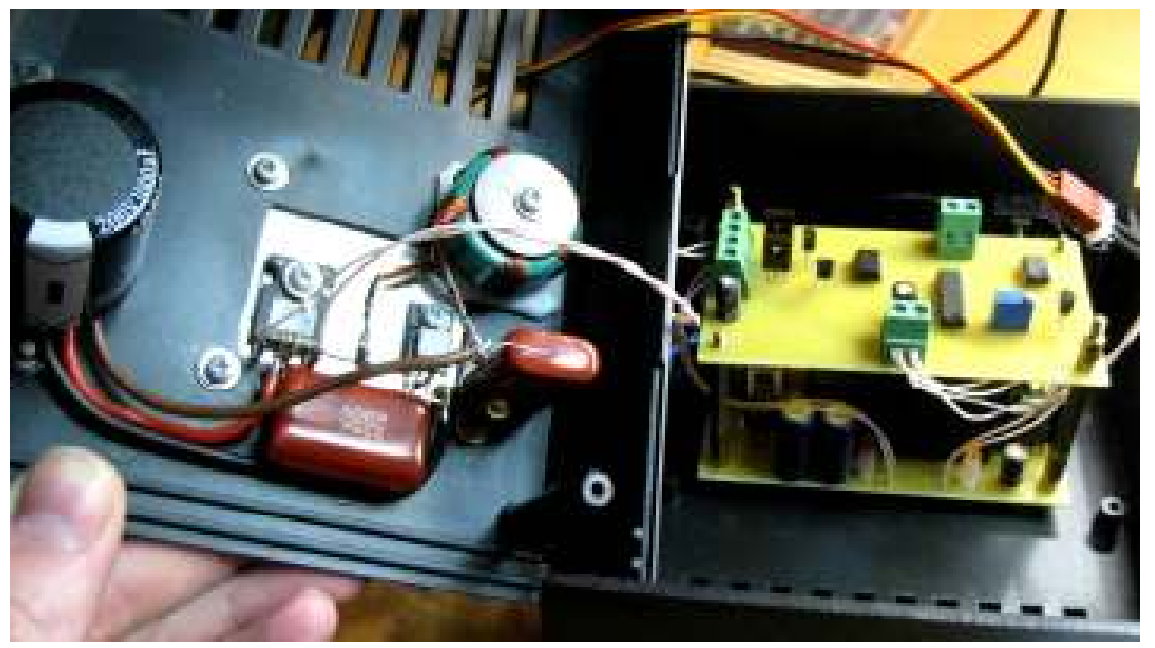

Рисунок 8 - Общий вид модулятора на основе Buck преобразователя 
«Системні технології» 4 (129) 2020 «System technologies»

Для проверки работы был подан синусоидальный сигнал на вход модулятора. С помощью микрофона была снят выходной сигнал с ВЧ коронного разряда и по данным вход / выход построен график (рис. 10).

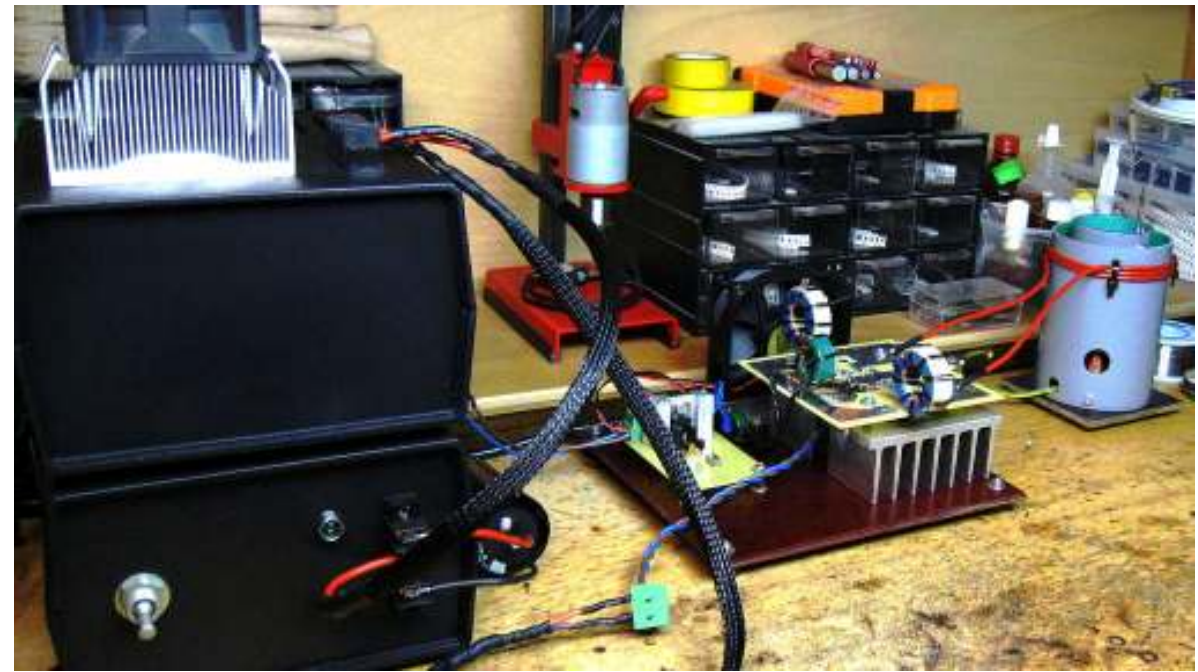

Рисунок 9 - Модулятор подключенный к устройству получения ВЧ коронного разряда

С помощью программы RightMark Audio Analyzer было проведено исследование работы модулятора. Коэффициент нелинейных искажений составил $0.8 \%$.

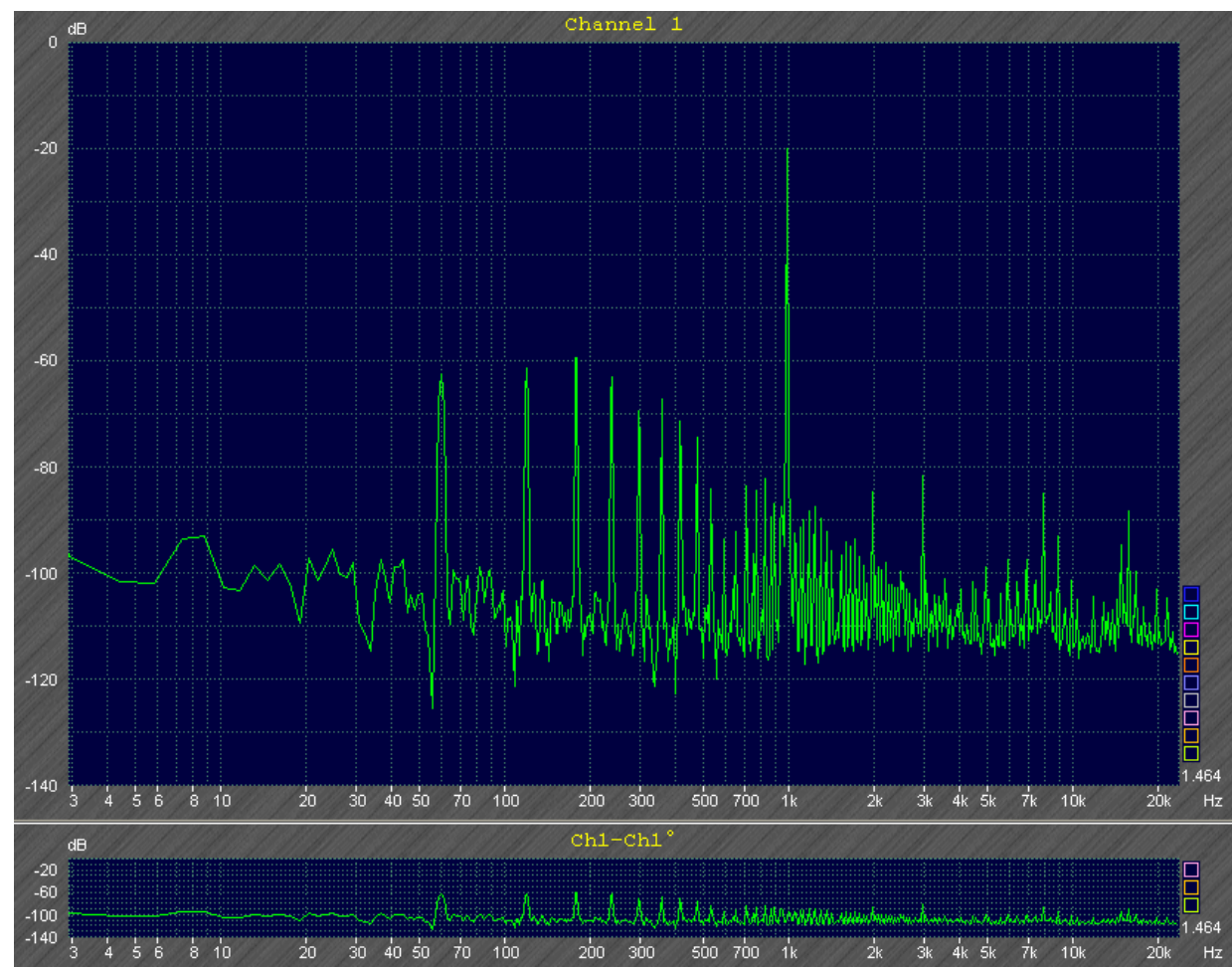

Рисунок 10 - Окно программы программы RightMark Audio Analyze 
«Системні технології» 4 (129) 2020 «System technologies»

Вывод. Созданный аппаратный комплекс позволяет получить высокочастотный коронный разряд, а модулятор на основе Buck преобразователя может быть применен в качестве управляющего элемента в области звуковых частот.

Коэффициент нелинейных искажений $0.8 \%$, что был получен в ходе исследования на разработанном и построенном аппаратном комплексе показывает адекватность данного метода управления.

\section{ЛИТЕРАТУРА / ЛІТЕРАТУРА}

1. Steve Roberts DC/DC book of knowledge / Steve Roberts // RECOM Group Gmunden 2014. - 234 p.

2. Marian K. Kazimierczuk Pulse-Width Modulated DC-DC Power Converters, 2nd Edition / Marian K. Kazimierczuk // Wright State University, Dayton, Ohio, USA 2008 - 960 p

3. Ю.П. Райзер Физика газового разряда / Ю.П Райзер - М.: Наука, 1992. 434c.

4. Хоровиц П. Искусство схемотехники / П. Хоровиц, У. Хилл. - М.: Мир,1995. - 154 с.

5. Зимогляд А.Ю. Development of a system for thermal evaporation / Зимогляд А.Ю., Гуда А.І. // Системні технології. Регіональний міжвузівський збірник наукових праць 2019 - №6 (119) С.-3-11.

6. Зимогляд А.Ю. Buck converter simulation and measurement / Зимогляд А.Ю., Гуда А.І. // Системні технології. Регіональний міжвузівський збірник наукових праць 2019 - №2 (121) С.-21-32.

7. Зимогляд А.Ю. Моделювання перетворювача топології Buck для системи управління нагрівачем у вакуумі / Зимогляд А.Ю., Гуда А.І., Михальов О.І. // АСУ та системи автоматики 2019 (176).

\section{REFERENCES}

1. Steve Roberts DC/DC book of knowledge / Steve Roberts // RECOM Group Gmunden 2014. - 234 p.

2. Marian K. Kazimierczuk Pulse-Width Modulated DC-DC Power Converters, 2nd Edition / Marian K. Kazimierczuk // Wright State University, Dayton, Ohio, USA 2008 - 960 p

3. Yu.P. Reiser Physics of gas discharge / Yu. P. Reiser - M .: Nauka, 1992. 434p.

4. Horowitz P. The Art of radio electronics / P. Horowitz, W. Hill. - M .: Mir, 1995. - $154 \mathrm{p}$. 
«Системні технології» 4 (129) 2020 «System technologies»

5. Zymoglyad A.Yu. Development of a system for thermal evaporation / Zymogl. A.Yu., Guda A.I. // System technologies. Regional Intercollegiate Collection of Scientific Papers 2019 - №6 (119) P.-3-11

6. Zymoglyad A.Yu. Buck converter simulation and measurement / Zymoglyu A.Yu., Guda A.I. // System technologies. Regional Intercollegiate Collection of Scientific Papers 2019 - №2 (121) P.-21-32

7. Zymoglyad A.Yu. Simulation of the Buck topology converter for the heater control system in vacuum / Zymoglyad A.Yu., Guda A.I., Mikhalev A.I. // ACS \& Automation Systems 2019 (176).

Received 02.03.2020. Accepted 06.03.2020.

Метод амплітудної модуляції високочастотного коронного розряду

Коронний розряд знайшов своє застосування в різних галузях науки і техніки. Коронний розряд, що протікає при високих частотах, застосовується для поверхневого легування металів і напівпровідників, для очищення газів від пилу в складі електростатичних фільтрів, для діагностики станів конструкцій. У статті наводяться результати дослідження з управління розрядом за допомогою амплітудної модуляції.

\section{Method of amplitude modulation high-frequency corona discharge}

The corona discharge has been applied in various branches of science and technology. Corona can be used to generate charged surfaces, which is an effect used in electrostatic copying (photocopying). They can also be used to remove particulate matter from air streams by first charging the air, and then passing the charged stream through a comb of alternating polarity, to deposit the charged particles onto oppositely charged plates.

Corona is one of the phenomena connected with all energized electrical mechanisms, including high-voltage transmission lines. The localized electric field near a conductor can be reasonable concentrated to ionize air close to the conductors. So, it can result in a partial discharge of electrical energy called a corona discharge.

The condition for the appearance of this discharge reflects the physical mechanism of the reproduction of electrons in the area of the amplified field, where ionization occurs. The mechanism of electron multiplication depends on the polarity of the corona electrode. If it is a cathode, then the corona is called negative. Secondary process is emission from the cathode, also in a small region, stepwise ionization in the gas volume. If the corona electrode is an anode, then the corona is called positive. A remote large cathode, near which the field is weak, does not participate in reproduction, then secondary photoprocesses in the gas in the tip zone are responsible for the reproduction of electrons. In contrast to the smooth luminescence of the negative corona, there are filaments running away from the point in the positive corona. These threads are called streamers.

To study the phenomena that occur during a corona discharge, as well as to provide a high-frequency corona discharge and measure its physical properties, which are necessary for building models and a control system, a hardware complex was assembled.

The study considers the possibility of controlling the discharge in the range of sound frequencies using amplitude modulation. 
Зимогляд Андрей Юрьевич - ассистент каф. ИТС Национальной металлургической академии Украины.

Гуда Антон Игоревич - д.т.н, проф., доц. каф ИТС Национальной металлургической академии Украины.

Царик Владислав Юрьевич - аспирант каф. ИТС Национальной металлургической академии Украины.

Зимогляд Андрій рійович - асистент каф. ITC Національної металургійної академії України.

Гуда Антон Ігорович - д.т.н, проф., доц. каф ITC Національної металургійної академії України.

Царик Владислав Юрійович - аспірант каф. ITC Національної металургійної академії України.

Zimoglyad Andrey - assistant, post-graduate student, National Metallurgical Academy of Ukraine.

Guda Anton - doctor of engineering's sciences, professor, National Metallurgical Academy of Ukraine.

Tsaryk Vladyslav - postgraduate student, assistant professor, department of information technologies and systems, National Metallurgical Academy of Ukraine. 